Tính ứng dụng của nghiên cứu: Biết được tỷ suất cao trở thành TSNBN ở các bệnh nhẩn thai trứng lớn tuổi, Đánh giá được hiệu quả của các biện pháp dự phòng: cắt tử cung giúp làm giảm nguy cơ bị TSNBN, hóa dự phòng kết hợp với cắt tử cung cũng là lựa chọn tốt cho các bệnh nhân thai trứng lớn tuổi. Hóa dự phòng đơn thuần không làm giảm nguy cơ bị TSNBN ở các bệnh nhân thai trứng lớn tuổi. Qua đó giúp bác sĩ lâm sàng lựa chọn biện pháp quản lý sau hút nạo phù hợp, tư vấn tốt hơn giúp bệnh nhân hiểu và tuân thủ điều trị.

\section{KẾT LUẬN}

Tỷ suất TSNBN ở các bệnh nhân thai trứng lớn tuổi là $33.06 \%$. Các yểu tố liên quan đến TSNBN bao gồm tuổi $\geq 46$ và có triệu chứng ra huyết âm đạo. Phẫu thuật cắt tử cung dự phòng có hiệu quả ở các bệnh nhân thai trứng lớn tuổi, đủ con, giúp làm giảm nguy cơ TSNBN. Hóa dự phòng đơn thuần không nên thực hiện do không làm giảm nguy cơ bị TSNBN.

\section{TÀl LIẸU THAM KHẢO}

1. Trân Huy Nhât, Võ Tuấn Minh, Lê Tư Phương

Chi (2014). "Kết quả hóa dự phòng ở bệnh nhân thai trứng nguy cơ cao tại bểnh viện Từ Dũ". Tập san Y học TP HCM, tập 18 (1), pp. 58-63.
2. Bakhtiyari Mahmood, Mirzamoradi Masoumeh, Kimyaiee Parichehr, et al. (2015). "Postmolar gestational trophoblastic neoplasia: beyond the traditional risk factors". Fertility and sterility, 104 (3), pp. 649-654.

3. Fu J., Fang F., Xie L., et al. (2012). "Prophylactic chemotherapy for hydatidiform mole to prevent gestational trophoblastic neoplasia". Cochrane Database Syst Rev, 10 (10), pp. Cd007289.

4. Giorgione $V_{.}$, Bergamini A., Cioffi $R_{.}$, et al. (2017). "Role of Surgery in the Management of Hydatidiform Mole in Elderly Patients: A SingleCenter Clinical Experience". Int J Gynecol Cancer, 27 (3), pp. 550-553.

5. Kaye D. K. (2002). "Gestational trophoblastic disease following complete hydatidiform mole in Mulago Hospital, Kampala, Uganda". Afr Health Sci, 2 (2), pp. 47-51.

6. Savage P. M., Sita-Lumsden A., Dickson S., et al. (2013). "The relationship of maternal age to molar pregnancy incidence, risks for chemotherapy and subsequent pregnancy outcome". J Obstet Gynaecol, 33 (4), pp. 406-11.

7. Wang Q., Fu J., Hu L., et al. (2017), "Prophylactic chemotherapy for hydatidiform mole to prevent gestational trophoblastic neoplasia". Cochrane Database Syst Rev, 9, pp. Cd007289.

8. Zhao P., Chen Q., Lu W. (2017). "Comparison of different therapeutic strategies for complete hydatidiform mole in women at least 40 years old: a retrospective cohort study". BMC Cancer, 17 (1), pp. 733.

\title{
ĐẶC ĐIỂM PHÁT TRIỂN TÂM-VÂ̂N ĐộNG Ở TRẺ TỰ KỶ TỪ 24 ĐẾN 72 THÁNG TUỔI TẠI THÁI NGUYÊN
}

\section{Lê Thị Kim Dung*, Nguyễn Thị Xuân Hương*, Hoàng Thị Huế*, Nguyễn Thị Phượng*, Bế Hà Thành*, Trần Tuấn Anh*}

\section{TÓM TẮT.}

Mục tiêu: Mô tả đặc điểm phát triển tâm-vận động ở trẻ từ 24 đến 72 tháng tuổi mắc rối loạn tự kỷ. Đối tượng và phương pháp: Nghiên cứu mô tả được thực hiện trên 161 trẻ từ 24 đên 72 tháng tuổi mắc rối loạn tự kỷ tại Thái Nguyên, thời gian từ năm 2014 đến 2017. Tự kỷ được chẩn đoán xác định theo tiêu chuẩn DSM-IV và phần loại mức độ theo thang điểm đánh giá tự kỷ (CARS), đặc điểm phát triển tâmvận động được đánh giá bằng test Denver II. Kết quả: Tuổi trung bình được chẩn đoán tự kỷ 29,87 \pm 4,2 tháng, tự kỷ gặp nhiều ở trẻ nam hơn trẻ nứ, tỉ lệ nam/nữ = 4,75/1; tự kỷ mức độ nặng chiếm tỉ lế khá cao $(70,2 \%)$. Trẻ tự kỷ chậm phát triển nhiều nhất ở

*Trường Đại học Y- Dược Thái Nguyên Chịu trách nhiệm chính: Lê Thị Kim Dung Email: lethikimdung@tnmc.edu.vn Ngày nhận bài: 19.3.2021

Ngày phản biện khoa học: 14.5.2021

Ngày duyệt bài: 25.5.2021 các lĩnh vực liên quan đến giao tiếp như: châm phát triển ngôn ngữ (95,03\%); chậm phát triển lĩnh vực cá nhân-xã hội $(95,65 \%)$. Khoảng 73,91\% trẻ tự kỷ chậm phát triển vận động tinh tế, thích ứng và $25,47 \%$ trẻ tự kỷ chậm phát triển vận động thô. Trẻ tự kỷ chậm phát triển ở mức vừa và nặng $(\mathrm{DQ}<50)$ chiếm tỉ lê $59,0 \%$. Kết luân: Trẻ tự kỷ chậm phát triển nhiêu nhất ở các lĩnh vực liên quan đến giao tiếp như: chậm phát triển ngôn ngữ, chậm phát triển lînh vực cá nhân-xã hội $(95,65 \%)$. Trè tự kỷ chậm phát triển ở mức vừa và năng $(\mathrm{DQ}<50)$ chiếm tỉ lệ $59,0 \%$

Tư khóa: Tự kỷ, trắc nghiệm Denver II, ngôn ngữ, cá nhân-xã hội, phát triển tâm-vận động

\section{SUMMARY \\ CHARACTERISTICS OF PSYCHIATRY AND \\ MOVEMENT DEVELOPMENT IN CHILDREN WITH AUTISM FROM 24-72 MONTHS IN THAI NGUYEN \\ Objectives: Describe the characteristics of} psychiatry and movement development in children from 24 to 72 months of age with an autism spectrum 
disorder. Subjects and methods: A descriptive study was conducted on 161 children from 24 to 72 months of age with an autism spectrum disorder in Thai Nguyen, from 2014 to 2017. Autism was diagnosed according to DSM-IV and graded according to the autism assessment scale (CARS), psychomotor development characteristics were assessed by the Denver II test. Results: Average age at diagnosis of autism $29.87 \pm 4.2$ months, autism was more common in boys than girls, male/female ratio = 4.75/1; Severe autism accounted for a relatively high rate $(70.2 \%)$. Children with autism have the most delay in communication in areas related to communication such as language delay $(95.03 \%)$; retarded personal-social development (95.65\%). About $73.91 \%$ of children with autism have delays in fine and adaptive motor development and $25.47 \%$ of children with autism have gross motor delays. Children with autism have moderate and severe developmental delay (DQ < 50) accounting for $59.0 \%$. Conclusion: Children with autism have the most developmental delays in communication-related areas such as language delays, personal-social delays (95.65\%). Children with autism have moderate and severe developmental delay (DQ < 50) accounting for $59.0 \%$

Keywords: Autism, Denver II test, language, individual-society, psychiatry and movement development

\section{I. ĐĂT VẤN ĐỀ}

Tự kỷ là một rối loạn phức tạp về phát triển thần kinh ở mức độ từ nhe đến nặng, khởi phát sớm từ khi trẻ còn nhỏ (thường trước 3 tuổi) và diễn biến kéo dài với biểu hiện đặc trưng là khiếm khuyết về tương tác xã hội, ngôn ngữ, giao tiếp và hành vi định hình, rập khuôn, sở thích thu hẹp. Trên thế giới cũng như ở Việt Nam, tỉ lệ tự kỷ gia tăng một cách đáng lo ngại. Tại Việt Nam, theo nghiên cứu dịch tễ mới nhất về tự kỷ tại 8 tỉnh thành đại diện toàn quốc công bố năm 2019, tỉ lệ mắc tự kỷ ở trẻ 18-30 tháng là $0,758 \%$ [4]. Tại Thái Nguyên, khảo sát tự kỷ ở lứa tuổi từ 16-60 tháng tại cộng đồng ghi nhận tỉ lệ này là $0,45 \%$ và số trẻ tự kỷ đến can thiệp, điều trị ở bệnh viện và các trung tâm của địa phương ngày càng gia tăng nhanh chóng [3]. Điều này gây nhiều gánh nặng về vật chất, tinh thần cho gia đình trẻ tự kỷ và xã hội. Việc đánh giá phát triển tâm vận động ở trẻ tự kỷ, không chỉ giúp sàng lọc mà còn giúp các cán bộ can thiệp lựa chọn được chiến lược can thiệp phù hợp và hiệu quả cho mỗi trẻ. Thực tế này thúc đẩy chúng tôi tiến hành nghiên cứu đề tài này với mục tiêu: Mô tả đặc điểm phát triển tâm-vận động ở trẻ mắc tự kỷ tại Thái Nguyên.

\section{II. ĐỐI TƯỚNG VÀ PHƯƠNG PHÁP NGHIÊN CỨU}

2.1. Đối tượng nghiên cứu. Trẻ từ 24 tháng đến 72 tháng tuổi tại Thái Nguyên được chẩn đoán tự kỷ theo tiêu chuẩn của DSM-IV. Cha me đẻ của trẻ đồng ý hợp tác nghiên cứu.

2.2. Thời gian và địa điểm nghiên cứu. Nghiên cứu đước tiến hành tai Bênh viên Chỉnh hình và Phục hồi chức năng Thái Nguyên (BVCH \& PHCN Thái Nguyên) và Trung tâm Tư vấn hỗ trợ giáo dục dạy nghề cho trẻ thiệt thòi Thái Nguyên từ năm 2014 đến năm 2017.

\subsection{Phương pháp nghiên cứu:}

Thiết kế nghiên cứu : Nghiên cứu mô tả cắt ngang

Cỡ mầu: Sử dụng công thức mô tả 1 tỉ lệ

$$
n=Z_{1-\alpha / 2}^{2} \frac{p q}{d^{2}}
$$

Trong đó: $\mathrm{n}$ là cỡ mẫu tối thiểu cần chọn; $\mathrm{p}$ : tỉ lệ trẻ tự kỷ có quan hêe xã hội, thể hiện tình cảm kém (ước tính theo nghiên cứu của của Vũ Thị Bích Hạnh là 89,23\%) [1]; q = 1- p. $Z_{1-\alpha / 2}$ là hệ số giới hạn tin cậy, với mức tin cậy $95 \%$ $\rightarrow Z_{1-a / 2}=1,96 ; d$ là độ chính xác mong muốn là $5 \% \rightarrow$ Thay vào công thức tính được cỡ mẫu tối thiểu là 148 trẻ. Thực tế chúng tôi đã lựa chon được 161 trẻ (130 trẻ ở BVCH \& PHCN tỉnh Thái Nguyên và 31 trẻ ở Trung tâm tư vấn hỗ trợ giáo dục dạy nghề cho trẻ thiệt thòi Thái Nguyên).

Biến số, chỉ số nghiên cứu: Tuổi của trẻ ở thời điểm nghiên cứu (tính theo tháng); giới tính: nam, nữ; khu vực sống: (thành thị, nông thôn); dân tộc: Kinh, dân tộc khác dân tộc Kinh; mức độ tự kỷ theo thang điểm CARS: tự kỷ nhẹvừa, tự kỷ nă̆ng.

Sử dụng test Denver II để đánh giá phát triển tâm-vận động ở trẻ tự kỷ [8]. Các lĩnh vực phát triển tâm-vận động được đánh giá: (1) Lĩ̄nh vực cá nhân - xã hội: đánh giá khả năng nhận biết bản thân, chăm sóc bản thân và thiết lập quan hệ tương tác với người khác. (2) Lĩnh vực vận động tinh tế - thích ứng: đánh giá khả năng vận động khéo léo của đôi tay và khả năng quan sát tinh tế của đôi mắt. (3) Lĩnh vực ngôn ngũ (ngôn ngữ nghe hiểu và ngôn ngữ nói): đánh giá khả năng lắng nghe và đáp ứng với âm thanh, khả năng phát âm, và sau cùng là khả năng phát triển ngôn ngữ. (4) Lĩnh vực vận động thô: đánh giá khả năng phát triển các vận động toàn thân và khả năng giữ thăng bằng của cợ thể.

Chỉ số phát triển (DQ) được ước lượng như sau: $\mathrm{DQ}=$ (tuổi phát triển $\times 100$ )/tuổi thực

DQ từ 90-100: bình thường; $D Q$ từ 75-90: dưới mức bình thường

DQ từ 50-75: chậm mức độ nhẹ, trung bình; DQ < 50: chậm mức độ nặng [8]

\section{* Phương pháp thu thập số liệu}


(1) Giải thích cho cha/mẹ đẻ trực tiếp nuôi dưỡng trẻ về mục đích, ý nghĩa phương pháp tiến hành nghiên cứu; (2) Phỏng vấn và quan sát trẻ theo phiếu điều tra; (3)Tiến hành thăm khám, phỏng vấn, quan sát và đánh giá phát triển tâm-vận động ở trẻ tự kỷ theo test Denver II (do bác sĩ tâm thần Nhi khoa, cán bộ tâm lý và bác sĩ chuyên khoa Nhi thực hiện).

*Xử lý số liệu: Sử dụng các test thống kê thích hợp. Số liệu được phân tích và xử lý phần mềm Stata 14 (StataCorp LP, College Statation, TX).

\section{KẾT QUẢ NGHIÊN CỨU}

\section{1. Đặc điểm chung của đối tượng} nghiên cứu

Bảng 3.1. Đặc điểm chung của đôî tượng tham gia nghiển cứu

\begin{tabular}{|c|c|c|c|}
\hline \multicolumn{2}{|c|}{$\begin{array}{l}\text { Đăc điểm chung của } \\
\text { đôî́ tượng nghiên cứu }\end{array}$} & & \\
\hline \multirow{3}{*}{ Nhóm tuổi } & 24-35 tháng & $51(31,7)$ & \multirow{2}{*}{0,001} \\
\hline & 36-72 tháng & $110(68,3)$ & \\
\hline & $(T B \pm S D)^{*}$ & \multicolumn{2}{|c|}{$44,01 \pm 13,84$} \\
\hline \multirow{2}{*}{ Giới tính } & Nam & $133(82,6)$ & \multirow{2}{*}{0,001} \\
\hline & N & & \\
\hline \multirow{2}{*}{$\begin{array}{l}\text { Khu vực } \\
\text { sống }\end{array}$} & Thành thị & $101(62,7)$ & \multirow{2}{*}{0,001} \\
\hline & Nông thôn & $60(37,3)$ & \\
\hline \multirow{2}{*}{ Dân tộc } & Kinh & $124(77,0)$ & \multirow{2}{*}{0,001} \\
\hline & Khác & $37(23,0)$ & \\
\hline
\end{tabular}

(*): TB: giá trị trung bình, SD: độ lệch chuấn

Nhận xét: Trẻ tự kỷ tham gia nghiên cứu có tuổi từ 36-72 tháng nhiều hơn trẻ từ 24-35 tháng; tự kỷ ở trẻ nam gặp nhiều hơn trẻ nữ, tỉ lệ trẻ nam/trẻ nữ là 4,75/1; trẻ tự kỷ sinh sống ở khu vực thành thị nhiêu hơn khu vực nông thôn, trẻ tự kỷ người dân tộc Kinh chiếm tỉ lệ cao hơn người dân tộc khác $(p<0,001)$.

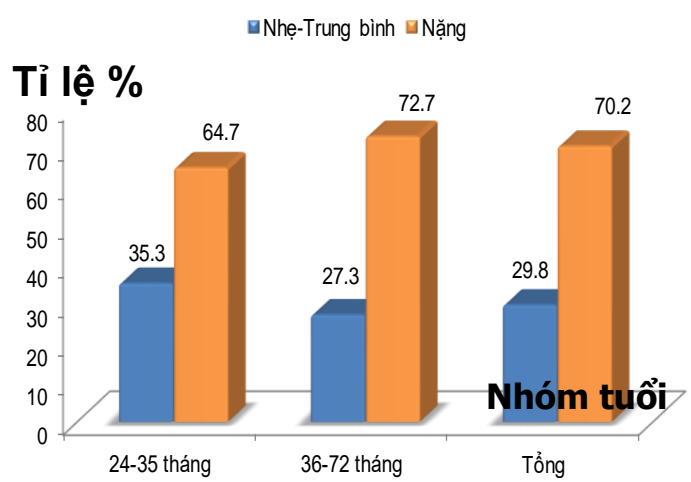

Biêu đồ 3.1. Phân loại mức độ của tự kỷ theo thang điểm CARS

Nhận xét: Kết quả đánh giá mức độ tự kỷ (sử dụng thang điểm CARS) cho thây trẻ tự kỷ ở mức độ nặng chiếm tỉ lệ $70,2 \%$. Không nhận thây sự khác biệt về mức độ tự kỷ ở 2 nhóm tuổi
24-35 tháng và 36-72 tháng ( $p>0,05)$.

3.2. Đặc điểm phát triển tâm-vận động của trẻ tự kỷ

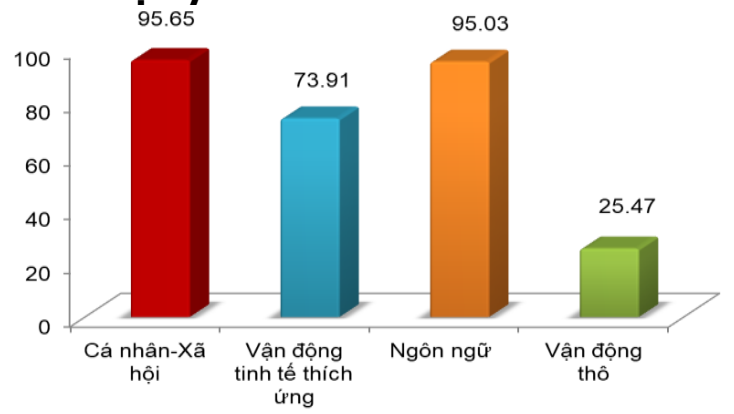

Biểu đồ 3.2. Tỉ lệ chậm phát triển ở các lĩnh vức của trẻ tứ kỷ

Nhận xét: Kết quả đánh giá sự phát triển ở các lĩnh vực của trẻ tự kỷ, nhận thấy trẻ chậm phát triển nhiều nhất ở các lĩnh vực liên quan đến giao tiếp như: 95,65\% trẻ có tình trạng chậm phát triển lĩnh vực cá nhân-xã hội; 95,03\% trẻ tự kỷ chậm phát triển ngôn ngữ.

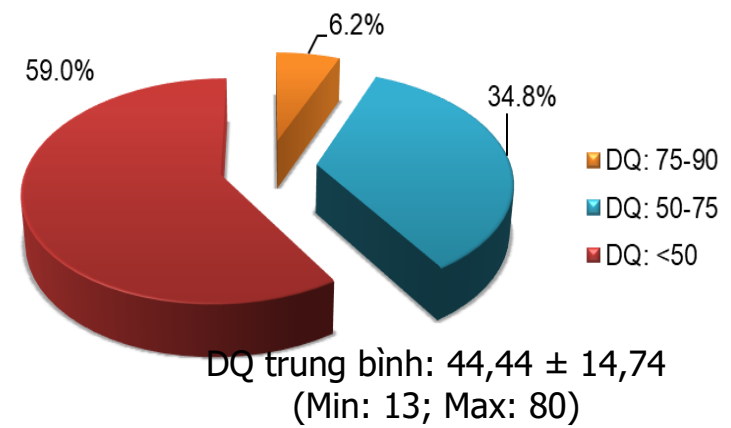

Biểu đồ 3.3. Phân bố mức độ phát triển của tré theo chi sô $D Q$

Nhận xét: Trẻ tự kỷ chậm phát triển ở mức vừa và nặng $(\mathrm{DQ}<50)$ chiếm tỉ lệ $59,0 \%$.

\section{BÀN LUẬN}

Nghiên cứu của chúng tôi tiến hành mô tả đặc điểm phát triển tâm-vận động trên 161 trẻ tự kỷ từ 24 tháng đến 72 tháng tuổi tại Thái Nguyên.

4.1. Đặc điểm chung của đối tượng nghiên cứu. Nhóm trẻ tự kỷ trong nghiên cứu

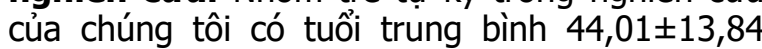
tháng (thấp nhất: 24 tháng, cao nhất: 71 tháng). Trong 161 trẻ rối loạn phổ tự kỷ, tham gia nghiên cứu của chúng tôi gặp chủ yếu là trẻ nam chiếm tỉ lệ $82,6 \%$, với tỉ lệ nam/nữ: $4,75 / 1$, sự khác biệt này có ý nghĩa thống kê $(p<0,05)$, tương tự như nghiên cứu của các tác giả trong và ngoài nước. Lai M.C và CS (2017) cho rằng chẩn đoán tự kỷ ở nam giới vượt trội so với nữ giới, có thể do nữ và nam khác nhau về kiểu 
hình tự kỷ, nữ giới có thể bị nhầm lẫn với bênh tâm thần [7]. Tại tỉnh Thái Nguyên với 46/54 dân tộc sinh sống, tỉ lệ dân tộc Kinh so với dân số trong tỉnh chiếm $73,1 \%$. Do đó, phân bố dân tộc trong nghiên cứu của chúng tôi đa số là dân tộc Kinh, chiếm $77 \%$ là phù hợp. Ngoài ra, có $62,7 \%$ trẻ tự kỷ trong nghiên cứu của chúng tôi cư trú ở vùng thành thị, tương tự nghiên cứu của các tác giả khác [6], phải chăng do cha/mẹ ở vùng thành phố được tiếp cận với nhiều thông tin hơn nên những trẻ này được đưa đến khám và phát hiện tự kỷ nhiều hơn? Nhưng cũng có thể do mức độ đô thị hóa ngày càng tăng, ô nhiễm môi trướng ngày càng nhiều. Do vậy, việc tiếp xúc với các yếu tố ô nhiễm môi trường, đặc biêt là môi trường không khí trong thời kỳ mang thai của mẹ và thời thơ ấu của trẻ có thể tiềm ẩn mối nguy cơ mắc tự kỷ, trong khi đó các chất gây ô nhiễm không khí nguy hiểm thường tập trung ở môi trường đô thị. Vì vậy mà tỉ lệ trẻ tự kỷ ở khu vực thành thị cao hơn vùng nông thôn [6]. Tuy nhiên, cũng có thể còn có những yếu tố khác liên quan đến vấn đề này cần được nghiên cứu sâu và rộng hơn nữa.

Ở biểu đồ 3.1, chúng tôi sử dụng thang điểm CARS để đánh giá mức độ nặng của tự kỷ, điểm CARS trung bình $39,74 \pm 5,11$ (thấp nhất: 31 điểm, cao nhất: 53 điểm). Khoảng 70,2\% trẻ tự kỷ trong nghiên cứu của chúng tôi ở mức độ nặng (CARS $\geq 37$ điểm, thấp hơn nghiên cứu của Đoàn Thị Ngọc Hoa $(75,2 \%)$ [2], có thể do tác giả chọn trẻ tự kỷ tại bệnh viện tuyến Trung ương, nơi chủ yếu trẻ đến khám và điều trị là những trẻ tự kỷ điển hình nên trẻ tự kỷ mức độ nặng chiếm tỉ lệ cao hơn. Tham gia vào nghiên cứu của chúng tôi, trẻ được chọn vào nghiên cứu là những trẻ sống trong khu vực tỉnh Thái Nguyên, ngoài can thiệp tại bệnh viện còn có trẻ can thiệp tại các trung tẩm tư nhẩn và những trường hợp nhẹ hơn chỉ can thiệp tại gia đình, cũng có thể vì vậy mà số trẻ tự kỷ trong nghiên cứu của chúng tôi ở mức độ nặng chiếm tî lệ ít của các tác giả khác.

4.2. Đặc điểm phát triển tâm-vận động của trẻ tự kỷ. Chúng tôi sử dụng test Denver II để đánh giá phát triển tâm-vận động của trẻ tự kỷ, bởi test này là công cụ rẩt hứu ích cho việc đánh giá các vấn đề về tâm-vận động của trẻ tự kỷ dưới 6 tuổi. Kết quả ở biểu đồ 3.2 và 3.3 cho thấy, chỉ số $D Q$ trung bình ở trẻ tự kỷ trong nghiên cứu của chúng tôi là rất thấp, chỉ số $\mathrm{DQ}$ trung bình là: $44,44 \pm 14,74$ (DQ cao nhất: 80 , $\mathrm{DQ}$ thấp nhất: 13 ), chỉ số $\mathrm{DQ}<50$ chiếm tới $59 \%$; đánh giá về các lĩnh vực phát triển của trẻ tự kỷ, chúng tôi nhận thấy có đến $95,03 \%$ trẻ chậm ngôn ngữ, 95,65\% trẻ có tình trạng chậm phát triển lĩnh vực cá nhân-xã hội. Kết quả này tương tư như nghiên cứu của Gulati Sheffali và cs (2019) trên 128 trẻ tự kỷ thì tỉ lệ trẻ mắc tự kỷ có $\mathrm{DQ} \leq 50$ là $60,2 \%$ [5] và nghiên cứu của Đoàn Thị Ngọc Hoa (2017) trên 117 trẻ rối loạn phổ tự kỷ, cho thây $100 \%$ số trẻ tự kỷ này đều không phát triển phù hợp tuổi ở lî́nh vực ngôn ngữ và cá nhân xã hội, hầu hết ở mức độ nặng và rất nặng gặp với tỉ lệ $96,6 \%$ [2]. Chậm phát triển về ngôn ngữ và các kỹ năng cá nhân xã hội là một đặc điểm phổ biến của trẻ tự kỷ, nếu biểu hiện ở mức độ trầm trọng sẽ làm nặng thêm mức độ của tự kỷ, gây ra nhiều rào cản cho can thiệp. Theo dối và đánh giá phát triển định kỳ ở một số mốc tuổi quan trọng như 12 tháng, 18 tháng và 24 tháng có thể giúp phát hiện sớm các rối loan phát triển, trong đó có tự kỷ. Hiệp hôi Nhi khoa Mỹ đã đưa ra khuyến cáo sàng lọc phát triển và tự kỷ nên được thực hiện đồng loạt cho trẻ em ở tuổi 18 tháng, 24 tháng. Chúng tôi nhận thấy rằng việc đánh giá toàn diện các lĩnh vực phát triển của trẻ là rất cần thiết nhằm phát hiện sớm các bất thường về phát triển của trẻ nói chung và phát hiện sớm tự kỷ nói riêng, đồng thời giúp đánh giá được các khiếm khuyết về các lĩnh vực của phát triển tâm-vận động ở trẻ tự kỷ, từ đó các bác sĩ và cán bộ can thiệp có thêm căn cứ lựa chọn được chương trình can thiệp phù hợp, hiệu quả cho trẻ tự kỷ.

\section{KẾT LUẦN}

Trẻ tự kỷ chậm phát triển nhiều nhất ở các lĩnh vực liên quan đển giao tiếp như: chậm phát triển ngôn ngữ $(95,03 \%)$; chậm phát triển lĩnh vực cá nhân-xã hội $(95,65 \%)$.

$73,91 \%$ trẻ tự kỷ chậm phát triển về vận động tinh tế, thích ứng và $25,47 \%$ trẻ tự kỷ chậm phát triển vận đônng thô.

Trẻ tự kỷ chậm phát triển ở mức vừa và nặng (DQ <50) chiếm tỉ lệ 59,0\%.

\section{TÀI LIÊU THAM KHẢO}

1. Vũ Thị Bích Hạnh, Nguyễn Thanh Thủy, Đinh Thi Hoa (2016), "Mô tả đặc điểm lâm sàng ở trẻ tự kỷ và bước đâuu nhận xét kết quả phục hối chức năng ngôn ngữ"', Tạp chí Y học lâm sàng, Số chuyên đề Hội nghị Khoa học Bệnh viện Bạch Mai lần thứ 28, tr. 295-299.

2. Đoàn Thị Ngọc Hoa, Nguyễn Thị Thanh Mai (2017), "Khảo sát đặc điểm giấc ngủ của trẻ tự kỷ", Tạp chí Y học Việt Nam, Tập 459, tháng 10, số 2, tr. 192-195.

3. Pham Trung Kiên, Lê Thị Kim Dung và cộng sư (2014), "Nghiên cứu tỉ lệ hiên mắc và kết quả điều trị tự kỷ trẻ em tại Thái Nguyên", Y học 
Thành phố Hồ Chí Minh, 18(4) tr. 74-79.

4. Lê Thị Vui (2020), Dịch tễ học rối loạn phổ tự kỷ ở trẻ 18-30 tháng và rào cản tiếp cân dich vư chẩn đoán, can thiêp rồi loạn phổ tự kỷ tai Việt Nam, 2017-2019, Luấn án tiến sỹ. Đai học Y Hà Nội.

5. Gulati Sheffáli, Kaushik Jaya Shankar, Saini Lokesh, et al (2019), "Development and validation of DSM-5 based diagnostic tool for children with Autism Spectrum Disorder", PloS one, 14 (3), 14 (3), pp. 1-11

6. Hoang Van Minh, Le Thi Vui, Chu Thi Thuy Quynh, et al (2019), "Prevalence of autism spectrum disorders and their relation to selected socio-demographic factors among children aged 1830 months in northern Vietnam, 2017", International journal of mental health systems, 13 , pp. 29-29.

7. Lai M.C, Lerch J.P, Floris D.L, al et (2017), "Imaging sex/gender and autism in the brain: Etiological implications", J Neurosci Res, 95 (1-2), pp. 380-397.

8. Sularyo Titi, Endyarni Bernie, Lestari Tri, et al (2012), "Role of Denver II and Development Quotients in the management of several pediatric developmental and behavioral disorders", Paediatrica Indonesiana, 52 (1), pp. 51-56.

\section{THỰC TRANG QUẢN LÝ ĐIỀU TRİ BỆNH NHÂN LAO/HIV TẠI TRAM Y TẾ XÃ CỦA TỈNH THÁI NGUYÊN}

\section{TÓM TẮT}

Mục tiêu: Mô tả thực trạng quản lý điều trị bệnh nhân lao/HIV tại trạm y tế xã của tỉnh Thái Nguyên năm 2019 - 2020 và phân tích môtt số yếu tố liên quan đến kết quả điều trị bệnh nhân lao/HIV. Đối tượng và phương pháp nghiên cứu: Nghiên cứu mô tả cắt ngang trên 60 cán bộ y tế xã và 103 bệnh nhân lao/HIV được quản lý tại xã năm 2019 - 2020. Kết quả nghiên cứu: Cán bộ y tế xã ghi chép sổ sách đầy đủ thông tin cho bênh nhân lao/HIV là 98,3\%, tỉ lệ bệnh nhân được cấp phát thuốc lao theo đúng thời gian quy định (7-10 ngày/lần) là $0 \%$, tỉ lê bệnh nhân được giám sát thường xuyên tại nhà là $70,0 \%$, tỉ lệ bệnh nhân lao phổi $\mathrm{AFB}(+) / \mathrm{HIV}$ được xét nghiệm đờm lân 1, 2, 3 lần lượt là 77,8\%, 74,1\%, $66,7 \%$. Tỉ lệ điều trị thành công lao/HIV là $93,3 \%$ (AFB $(+) / H I V$ là $77,8 \%)$. Các yếu tố liên quan đến kết quả điều trị lao/HIV là tuổi, nghề nghiệp, kinh tế gia đình, điều trị phối hợp ARV và Cotrimoxazole của bệnh nhân lao/HIV.

Tư khóa: Lao/HIV, quản lý, điêu trị, Thái Nguyên.

\section{SUMMARY \\ MANAGEMENT AND TREATMENT OF TB/HIV \\ PATIENTS AT THE COMMUNE HEALTH \\ CENTER OF THAI NGUYEN PROVINCE}

Objectives: To describe the management and treatment of TB/HIV patients at the Commune Health Center in Thai Nguyen province and analysis some factors related to TB/HIV treatment outcomes. Subjects and research methods: A cross-sectional study among 60 commune health workers and 103 TB/HIV patients who were managed at the community health centers in 2019, 2020. Results: $98.3 \%$

${ }^{1}$ Bệnh viện Lao và Bệnh phổi Thái Nguyên

2Trường Đai hoc Y Dược Thái Nguyên

Chịu trách nhiệm chính: Trần Văn Tùng

Email: tungbvitn@gmail.com

Ngày nhận bài: 22.3.2021

Ngày phản biên khoa hoc: 17.5.2021

Ngày duyệt bài: 25.5.2021 commune health workers adequately recorded TB/HIV patients; the percentage of correctly providing TB/HIV drugs for patients (7-10 days/time) was $0 \%$; the percentage of regular monitoring patients at home was $70.0 \%$; patients with TB AFB $(+) / \mathrm{HIV}$, who were tested 1st, 2nd and 3th times, were $77.8 \% 74.1 \%$, $66.7 \%$, respectively. The successful treatment rate of TB/HIV patient and AFB (+)/HIV were $93.3 \%$ and $77.8 \%$, respectively. The related factors with TB/HIV treatment outcomes were age, occupation, family economics, treatment combination between ARV and Cotrimoxazole of TB/HIV patients.

Keywords: TB/HIV, Management, Treatment, Thai Nguyen.

\section{I. ĐĂT VẤN ĐỀ}

Bệnh lao là bệnh nhiễm trùng cơ hội phổ biến nhất gây tử vong ở những người nhiếm HIV. Tổ chức Y tế thế giới (WHO) ước tính năm 2019 có khoảng 10 triệu người mắc lao, trong đó 820.000 trường hợp mắc và 208.000 tử vong do đồng nhiếm lao/HIV. Việt Nam là nước có gánh nặng bệnh lao cao, đứng thứ 22 trong 30 nước có số người đồng nhiễm lao/HIV cao nhất trên thế giới. Quản lý điều trị lao cho người có HIV rất khó khăn bởi phải phối hợp nhiều loại thuốc trong điêuu trị lao, thuốc điêu trị HIV gây nhiêuu tác dụng phụ dễ dẫn tới gián đoạn điêuu trị. Hơn nữa, người nhiễm HIV tại Việt Nam chiếm tỉ lệ cao vẫn là nhóm đối tượng nghiện chích ma tuý do đó việc không tuân đúng theo sự chỉ dẫn của cán bộ y tế là rất thường xuyên [2]. Tuy nhiên, nếu quản lý điêu trị tốt đồng thời cả lao và HIV sẽ cải thiện được kết quả điều trị lao, làm giảm tỉ lệ tử vong [8]. Tỉnh Thái Nguyên có 178 xã, phường, thị trấn với nhiêu xã có lao/HIV. Vậy thực trạng quản lý điêuu trị lao/HIV tại các xã hiện nay như thế nào? Nhằm làm rõ vấn đề đó, chúng tôi tiến hành nghiên cứu: "Thực trạng 